\title{
PERCEPCIÓN DE LÍDERES SOCIALES Y REPRESENTANTES DE ORGANIZACIONES PÚBLICAS Y PRIVADAS SOBRE LA MIGRACIÓN Y LOS INMIGRANTES VENEZOLANOS EN EL MUNICIPIO DE MAICAO (LA GUAJIRA, COLOMBIA)*
}

\section{PERCEPTION OF SOCIAL LEADERS AND REPRESENTATIVES OF PUBLIC AND PRIVATE ORGANIZATIONS ON VENEZUELAN MIGRATION AND IMMIGRANTS IN THE MUNICIPALITY OF MAICAO (LA GUAJIRA, COLOMBIA)}

Jair Eduardo Restrepo-PIneda** y Juliana Jaramillo-Jaramillo***

Resumen: El artículo tiene por objetivo analizar la percepción que tienen líderes sociales y representantes de organizaciones públicas y privadas en el municipio de Maicao (La Guajira, Colombia) sobre el proceso migratorio y los inmigrantes venezolanos. Para este fin, se desarrolló una investigación cualitativa, utilizando como herramienta de investigación la entrevista semiestructurada. Se evidenció que existe una percepción negativa sobre el proceso migratorio de los venezolanos al catalogarlo como un problema,

* Los resultados de este estudio hacen parte del proyecto "Venezuelans in Colombia: Understanding the implications of the migrants crisis in Maicao (La Guajira)", desarrollado conjuntamente por la Corporación Universitaria Minuto de Dios - UNIMINUTO (Colombia) y la organización Sayara International. Los autores agradecen al equipo de investigación del proyecto y a la comunidad de Maicao por su participación en el estudio.

** Corporación Universitaria Minuto de Dios (Colombia). jair.restrepo@ uniminuto.edu

*** Corporación Universitaria Minuto de Dios (Colombia). j.jaramilloj@ uniandes.edu.co 
debido entre otros factores al volumen y la composición de clase social de la población inmigrante involucrada y la duración del movimiento migratorio. Las percepciones de los entrevistados son consistentes con la teoría de conflicto grupal que plantea que en contextos económicos desfavorables y con una elevada presencia de migrantes, se incrementa la competencia por bienes y servicios sociales limitados, lo cual conduce a que la inmigración sea considerada una amenaza para los autóctonos.

Palabras clave: migración; percepción; estereotipo; Colombia; Venezuela.

Abstract: The article analyzes the perception of social leaders and representatives of public and private organizations about the migratory process and Venezuelan immigrants in the municipality of Maicao (La Guajira, Colombia). A qualitative research was developed using semi-structured interviews. Results show that there is a negative perception about the migratory process of Venezuelans, due among other factors to the high volume of immigrants, their socioeconomic background, and the length of the migratory process. The perceptions of the participants are consistent with the group conflict theory that states that in unfavorable economic contexts with a high presence of migrants, the competition for limited social goods and services increases, which leads to immigration being considered as a threat by natives.

Key words: migration; perception; stereotype; Colombia, Venezuela.

\section{INTRODUCCIÓN}

La migración de venezolanos en los últimos años se ha convertido en un acontecimiento con un alto impacto tanto para Venezuela como para los países receptores de los flujos migratorios, donde las demandas sociales, económicas y políticas de quienes migran han generado nuevas presiones a los sistemas políticos y de protección social. Colombia por su relación histórica de migración con Venezuela (García \& Restrepo, 2019), pero además por su cercanía geográfica, se ha convertido en uno de los principales destinos para los ciudadanos venezolanos, lo que ha generado un aumento considerable en la llegada de estos a diferentes ciudades del país, pero con es- 
pecial impacto en las ciudades fronterizas, como lo es el municipio de Maicao en el departamento de La Guajira, donde se encuentra el puesto de control fronterizo de Paraguachón (Consejo Nacional de Política Económica y Social [CONPES], 2018; Migración Colombia, 2018).

De acuerdo con estadísticas oficiales, para septiembre de 2018 se encontraban residiendo en Colombia 1.032.016 migrantes venezolanos, entre regulares e irregulares (CONPES, 2018). Las razones que explican este tipo de movimientos migratorios van desde los intercambios supranacionales y la integración económica y política (Castells, 1997; Portes, 2003) hasta el cambio del patrón migratorio motivado por una crisis nacional del orden político, social y económico inédita en la historia de Venezuela, que ha pasado de ser un país receptor de migrantes a convertirse en uno expulsor con bajas expectativas de retorno (De la Vega \& Vargas, 2014). Así, la migración actual de venezolanos responde a acontecimientos políticos y económicos multidimensionales, entre los que se pueden señalar la caída internacional de los precios del petróleo que ha impactado de manera significativa el producto interno bruto del país, afectando el poder adquisitivo, los salarios y la tasa de cambio, además, de una errónea política económica, que algunos autores señalan también como responsable de esta crisis (Reina, Mesa \& Ramírez, 2018). Todo este panorama ha venido acompañado de procesos de inestabilidad social y política.

Robayo (2013) sostiene que las migraciones son el reflejo de las dinámicas sociales, y por tanto a través de estas se generan lazos de interdependencia que evidencian desafíos para los países, a su vez que crean oportunidades que enriquecen socialmente a los Estados. Venezuela y Colombia han tenido una historia migratoria muy ligada. En primer lugar, con la llegada de colombianos al vecino país fomentada por la bonanza petrolera — sobre todo entre las décadas de 1970 y 1980 - (Álvarez de Flores, 2004), así como por el enfrentamiento entre los tres principales actores del conflicto armado colombiano - el Estado, la guerrilla y los paramilitares-, el cual generó el desplazamiento forzado y masivo de colombianos, tanto en el interior del país como hacia fuera del mismo (Álvarez de Flores, 2009; Internal Displacement Monitoring Centre, 2017; Organización Internacional para las Migraciones [OIM], 2018). Y más recientemente, con la inmigración de venezolanos a Colombia a raíz de los problemas sociales, económicos y políticos que se viven allí.- 
La llegada de miles de migrantes venezolanos a Colombia ha pasado de ser una cuestión anecdótica para convertirse en una realidad social y económica permanente para el país, siendo necesario ampliar los estudios sobre este proceso migratorio. Ya en el inicio de los primeros flujos migratorios provenientes de Venezuela, autores como Robayo (2013), Santana (2009) y Echeverry (2011) manifestaban la necesidad de indagar sobre estos procesos sociales. Por tanto, es necesario realizar investigaciones sobre el tema que permitan entender el proceso migratorio de los venezolanos a Colombia en toda su complejidad, de manera que se construya una mirada adecuada sobre este hecho por parte de la academia (Echeverry, 2011). El interés particular de este artículo se centra en analizar las percepciones que tienen algunos líderes sociales y representantes de organizaciones públicas y privadas que se encuentran ubicados en el municipio de Maicao respecto a la migración de los venezolanos a Colombia. Ya que estas percepciones condicionan las actitudes de los autóctonos, entre ellos las de las personas que toman decisiones desde las administraciones locales, su estudio es relevante pues ellas influyen en los procesos de integración social de los inmigrantes y en la toma de decisiones acerca del diseño e implementación de acciones de intervención social y la promoción de políticas sociales que pueden contribuir con la consolidación de dinámicas sociales de inclusión o, por el contrario, facilitar la discriminación, la estigmatización y la exclusión (Bourhis, Moïse, Perreault \& Senécal, 1997).

\section{MARCO TEÓRICO}

La Organización Internacional para las Migraciones (OIM, 2006) define la migración como el "movimiento de población hacia el territorio de otro Estado o dentro del mismo que abarca todo movimiento de personas sea cual fuere su tamaño, su composición o sus causas; incluye migración de refugiados, personas desplazadas, personas desarraigadas, migrantes económicos" (p. 41). El proceso migratorio es complejo, y para su estudio deben considerarse un conjunto de variables sociales, económicas y políticas tanto de los países de origen como de destino, así como los tiempos, las trayectorias y los sujetos involucrados. Es necesario, además, tener en cuenta que la migración internacional no es una cuestión reciente, ya que 
puede considerarse un hecho consustancial a los seres humanos. Sin embargo, en las últimas tres décadas las migraciones se han extendido con mayor fuerza en todo el mundo debido a los avances en los medios de comunicación y de transporte, así como por la globalización del mercado, tal como lo sostienen Oroza y Puente (2017) "en la actualidad existe una estrecha relación entre las migraciones y el fenómeno de la globalización, en un mundo donde la tecnología y el avance continuo en las comunicaciones forman parte indiscutible de la vida del migrante" (p. 11).

Generalmente, la decisión de iniciar el proceso migratorio se realiza como respuesta a una combinación de presiones e incentivos de carácter económico, social y político. Las desigualdades dentro de los países y entre éstos generan incentivos para desplazarse, además de que la búsqueda de ingresos motiva la movilidad de hombres y mujeres. Pero los factores económicos son apenas uno de los numerosos componentes que influyen en la decisión de migrar. Las expectativas migratorias pueden abarcar desde reunirse con el cónyuge que migró hasta escapar a la discriminación por razones de género, etnia, ideología política o religión. Así, la migración internacional fomentó que "la mayoría de los países desarrollados se han transformado en sociedades multiétnicas y aquellas que aún no han alcanzado tal carácter se mueven decididamente en esta dirección" (Massey et al., 1993, p. 436). Por esta razón, el análisis de la migración debe incluir no solo a los migrantes sino a las sociedades de acogida donde estos llegan a integrarse. Sin embargo, resulta fundamental diferenciar las migraciones que se dan entre países de ingresos altos y bajos, denominadas migraciones sur-norte, y aquellas que se presentan entre países con ingresos medios o bajos, llamadas migraciones sur-sur, siendo estas últimas de las cuales se ocupa el presente artículo. Para Bologna y Falcón (2016) las migraciones sursur se presentan

Entre países con diferencias más leves en su desarrollo económico, que comparten una posición periférica en el mundo, cuyas fronteras son permeables y que reconocen gradaciones en el interior, desde áreas fronterizas poco diferenciadas internacionalmente, hasta grandes ciudades, a menudo más semejantes a ciudades globales que a otras del mismo país. (p. 731)

Es indispensable entonces reconocer las percepciones y las actitudes que tiene la población autóctona frente a los migrantes, pues 
éstas vendrán a incidir en los procesos de inclusión social de esta población. Las actitudes pueden definirse como "la disposición de un individuo a valorar personas y objetos de su mundo de vida de forma favorable o desfavorable" (Cea, 2002, p. 88). Vale la pena decir que las actitudes negativas hacia la inmigración se sustentan sobre una serie de prejuicios y temores de distinto tipo, entendiendo el prejuicio, a partir de la definición de Wieviorka (1992, citado por González, 2017), como "una forma elemental de racismo que se vincula con el reforzamiento de desigualdades existentes entre los sujetos involucrados" (p. 75). Sin embargo, los prejuicios no son rígidos o inflexibles, sino específicos al contexto social en el que se producen y a los grupos implicados (Dovidio \& Gartner, 2010). Esto último se consideró al realizar el análisis del estudio, ya que el contexto social del municipio de Maicao presenta varias especificidades. Una de ellas se refiere a su ubicación geográfica como zona de frontera con Venezuela, lo que ha permitido establecer lazos culturales, sociales y económicos entre ambos países que han constituido una frontera permeable. Una segunda particularidad tiene que ver con la presencia de la etnia Wayúu, tanto en territorio colombiano como venezolano, lo cual ha llevado a que se establezca un vínculo ancestral que no reconoce fronteras y ha consolidado una dinámica social y cultural propia en la región (Holstein, 2010). Finalmente, una última está relacionada con el hecho de que al ser una zona fronteriza el número de migrantes que han ingresado al municipio en corto tiempo es mucho más alto si se compara con el de otras regiones no fronterizas, donde el flujo de migrantes se da de manera más lenta debido a la distancia geográfica que estos deben recorrer para llegar allí, así, por ejemplo, "Maicao es la ciudad con un mayor flujo, tras presentar 23.429 ingresos en enero de 2018" (CONPES, 2018, p. 59).

Las características de la región establecen la percepción que sobre el proceso migratorio puedan tener sus habitantes, entendiendo la percepción como una construcción involuntaria donde el sujeto establece prioridades y preferencias con base en diferencias cualitativas y cuantitativas de lo que se percibe (Vargas, 1994). Dentro de este proceso tiene gran importancia el contexto social. De acuerdo con Vargas (1994)

La manera de clasificar lo percibido es moldeada por circunstancias sociales. La cultura de pertenencia, el grupo en el que se está inserto en la sociedad, la clase social a la que se pertenece, influyen sobre las formas como es concebida la realidad, las 
cuales son aprendidas y reproducidas por los sujetos sociales. Por consiguiente, la percepción pone de manifiesto el orden y la significación que la sociedad asigna al ambiente. (p. 49)

En este orden de ideas, la percepción que pueden tener los habitantes de una ciudad fronteriza sobre el proceso migratorio no necesariamente es igual a la de aquellos que habitan ciudades en las cuales esta realidad no se vive de manera tan cercana. Como señala Vargas (1994)

La percepción debe ser entendida como relativa a la situación histórico-social pues tiene ubicación espacial y temporal, depende de las circunstancias cambiantes y de la adquisición de experiencias novedosas que incorporen otros elementos a las estructuras perceptuales previas, modificándolas y adecuándolas a las condiciones. (p. 50)

Esta situación se evidencia en los procesos migratorios entre Colombia y Venezuela, donde los cambios sociales, políticos y económicos que se han presentado en la última década han determinado no solo el sentido de los flujos migratorios, sino también la percepción que sobre este proceso y sobre los migrantes se ha consolidado en ambos países. Por lo tanto, la flexibilidad de las relaciones culturales y sociales facilita la reconfiguración de las experiencias de los individuos a través de la percepción que estos tienen de dichos procesos, de forma que estas relaciones son recreadas para adaptarse a las situaciones que así lo requieren (Vargas, 1994).

Entonces, la percepción que tienen los autóctonos sobre los migrantes no es estática y única, sino que responde a los cambios que se presentan en el contexto migratorio. Para Santamaría (2005) existe una representación imaginada del migrante y otra que puede llegar a ser fantaseada. Este autor considera que,

Puede ser significativo distinguir entre ese "inmigrante" cuya presencia cotidiana es constantemente elaborada y resignificada: representándolo como alguien que "no tiene papeles", que "vive hacinado y en condiciones deplorables", que "no tiene estudios" y "carece de trabajo", que "ha tenido que emigrar porque en su tierra se moría de hambre", que "provoca inseguridad", y que debido a su diferencia cultural no puede o le es muy difícil integrarse en la sociedad a la que ha llegado, entre otras cosas; de ese otro "inmigrante", mucho más fantasmático e "irreal" en su sentido estricto, pues no existe. (p. 123) 
Estas construcciones sociales del inmigrante pueden constituir estereotipos. Siguiendo a Aparici (1993), se puede decir que un estereotipo es una representación repetida frecuentemente que convierte algo complejo en algo simple, pero en el proceso de simplificación se distorsiona la representación y se pone mayor énfasis en algunos aspectos, mientras que se desconocen otros. La función primordial del estereotipo es categorizar el mundo real, darle significado a un aspecto específico y no a otro, permitiendo organizar la información. Este mismo autor sostiene que los estereotipos determinan las relaciones con las demás personas a través de las ideas que sirven para construir y a la vez reforzar un sistema de convenciones sociales, que actúa sobre grupos y no sobre individuos, manteniendo una alta uniformidad sobre el contenido que transmiten y con el cual describen a un determinado colectivo. Además, son efectivos siempre y cuando invoquen un consenso, donde se represente la opinión común acerca de un grupo social; sin embargo, este consenso suele ser menos real de lo que aparenta, pues generalmente las ideas sobre otros grupos sociales son el producto de estereotipos.

Los estereotipos suelen ser considerados el componente cognitivo del prejuicio; sin embargo, esto no es obligatorio en todos los casos, ya que pueden existir estereotipos sin una actitud social prejuiciosa. Los prejuicios serán, entonces, un juicio previo, creencias con una orientación y evaluación que puede ser negativa y positiva en relación con una categoría social. La discriminación será el comportamiento derivado del prejuicio, de modo que "el prejuicio es una predisposición categórica para aceptar o rechazar a las personas por sus características sociales reales o imaginarias" (Light, Keller \& Calhoun, 1991, p. 356).

Los estereotipos y los prejuicios pueden conducir a la discriminación de algunos grupos sociales, ya que ésta se basa en las relaciones entre diversos grupos y tiene sus raíces en la opinión que un grupo social tiene sobre otro. En este sentido, "los estereotipos dotan al sujeto de expectativas que influyen en las explicaciones de las conductas observadas, en la evaluación que hace del individuo o grupo y en la predicción de las conductas futuras que se esperan del mismo" (Mancha, 2018, p. 11). Sin embargo, se puede generar un problema cuando la percepción sobre los demás se basa exclusivamente en aspectos limitados y superficiales que producen y reproducen estereotipos que posteriormente podrán dar origen a la discriminación. 


\section{METODOLOGÍA}

Este trabajo se desarrolló a partir de una investigación cualitativa con un enfoque hermenéutico interpretativo. Se llevó a cabo en el municipio de Maicao (La Guajira, Colombia) donde se ubica el puesto de control fronterizo de Paraguachón en zona rural que limita con Venezuela.

\subsection{Técnicas de investigación}

Las técnicas de investigación que se utilizaron durante el estudio fueron la entrevista semiestructurada, la encuesta, el grupo focal y la narrativa personal. Sin embargo, para el caso de los actores institucionales, tanto gubernamentales como no gubernamentales, así como para los líderes de la comunidad, sólo se utilizó la entrevista semiestructurada.

\subsection{Selección de sujetos participantes}

Para la realización de las entrevistas a los líderes de la comunidad se utilizó el sistema de bola de nieve, mientras que para la selección de los informantes pertenecientes a las organizaciones no gubernamentales (ONG) nacionales e internacionales, así como a los informantes de las entidades gubernamentales, se realizó una selección de estos actores atendiendo a su rol en los temas referidos a la protección de los migrantes venezolanos en estado vulnerable en el municipio de Maicao.

\subsection{Criterios de inclusión para los líderes sociales y comunitarios}

Para la selección de los líderes de la comunidad del municipio de Maicao se establecieron los siguientes criterios de inclusión: i) varones y mujeres nativos de la región, ii) cualquier procedencia étnica, iii) mayores de edad (18 años en adelante), iv) residencia de manera continua por cinco años o más en la región, y v) personas reconocidas por la comunidad como líderes o referentes sociales. 
En cuanto a los representantes de actores gubernamentales y no gubernamentales, éstos debían cumplir con al menos uno de los siguientes criterios: i) desarrollar actividades y estrategias relacionadas con la protección de los migrantes venezolanos y defensa de los DD. HH., ii) tener representación y toma de decisiones a nivel normativo, político, así como participación en acciones de debate frente a las migraciones, iii) estar organizados en la comunidad y demostrar incidencia en la toma de decisiones relativas a la ejecución de programas con migrantes, iv) brindar cooperación técnica a instituciones gubernamentales y no gubernamentales en torno a la gestión de las migraciones, y v) trabajar jurídica y judicialmente la defensa, atención y solución de casos de vulneración de derechos de los migrantes.

\subsection{Consideraciones éticas}

Para garantizar el ejercicio de una buena práctica investigativa de acuerdo con criterios éticos, se tuvo en cuenta lo siguiente: i) se elaboró un documento de consentimiento informado mediante el cual se le brindó información certera a los participantes sobre los objetivos, el alcance de la investigación y los posibles beneficios y riesgos de participar en la misma; ii) se garantizó el consentimiento informado en la utilización de artefactos como grabadoras o cámaras fotográficas donde se involucró a los sujetos participantes; iii) se hizo uso adecuado, seguro y confidencial de la información obtenida y se protegió el nombre de los participantes mediante su anonimización; iv) se garantizó la participación voluntaria y autónoma; v) se otorgó a los participantes la garantía de recibir respuesta a cualquier pregunta y aclaración a cualquier duda acerca de los procedimientos, riesgos, beneficios y otros asuntos relacionados con la investigación y el tratamiento del sujeto; y vi) se seleccionaron los sujetos participantes en la investigación teniendo en cuenta los criterios de inclusión mencionados en la metodología.

\section{RESULTADOS}

Para este estudio se realizaron 23 entrevistas en el municipio de Maicao, de las cuales 13 corresponden a representantes de organiza- 
ciones - públicas o privadas-, y 10 a líderes sociales, entre los que se encuentran líderes sindicales, comunitarios, de partidos políticos y religiosos. Para conservar el anonimato y la confidencialidad de los informantes, así como las instituciones a las cuales pertenecen, sus testimonios se presentarán bajo una categoría genérica: "entrevistado 1", "entrevistado 2", etc.

En los siguientes apartados se presenta el análisis y discusión de los resultados obtenidos en las entrevistas.

\subsection{La migración percibida como un problema}

Tanto los líderes comunitarios como los representantes de las organizaciones públicas y privadas reconocen el hecho migratorio como un proceso consustancial al ser humano, que se ha presentado a lo largo de la historia y se seguirá presentado, así uno de los entrevistados manifiesta que:

Comenzamos a mirar el fenómeno que hoy no solamente está afectando a Maicao, a Colombia y gran parte de Latinoamérica, que es el fenómeno de la migración de la población venezolana, pero tenemos que decir que la migración es un fenómeno connatural del ser humano, las sociedades han emigrado toda la vida. Pero ese proceso de reconfiguración demográfica también trae algunas cosas buenas y algunas no tan buenas. (Entrevistado 1)

En este sentido, se evidencia que si bien se reconocen aspectos positivos de las migraciones también existen factores negativos, los cuales dependerán de tres factores principales que "determinarían el poder que tiene la migración para generar cambios en los países emisores o receptores: el volumen de población involucrada, la duración del movimiento y la composición de clases social" (Monetti, 2016, p. 25).

Dichos factores se hacen evidentes en el municipio de Maicao, en primer lugar, porque el volumen de migrantes que ha llegado en los últimos años va en aumento. Según datos de Migración Colombia (2018), en el año 2014 ingresaron por el puesto fronterizo de Paraguachón 80.675 venezolanos, en el 2015 después del cierre de la frontera por parte del gobierno venezolano el número de migrantes descendió a 3.394, para el año 2016 se alcanzaron los 106.804, y finalmente, en el año 2017 el número de migrantes registrados a 
través de este punto de control fronterizo fue de 432.829. En el lapso de cuatro años se registraron entonces 623.702 ingresos de personas a través del municipio de Maicao, cumpliéndose entonces dos de los factores que menciona Monetti (2016) sobre el volumen y la duración del movimiento.

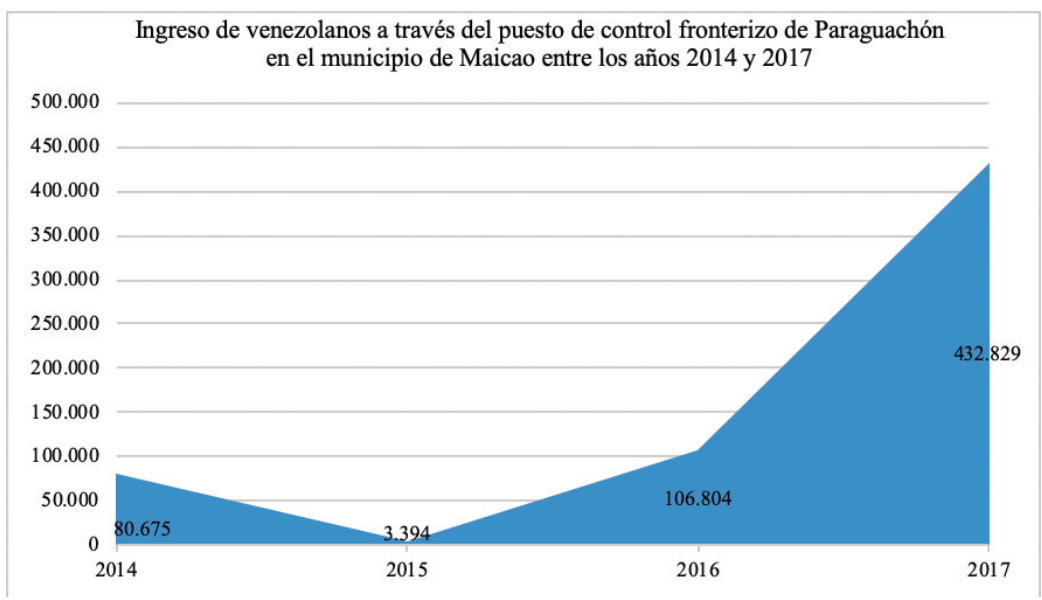

Fuente: elaboración propia con base en datos de Migración Colombia, 2018.

Además, según el CONPES (2018), la migración de venezolanos a Colombia ha ejercido una fuerte presión en los municipios de frontera, especialmente en diez de estos por donde han ingresado el 94\% de los ciudadanos venezolanos que se encuentran censados en el Registro Administrativo de Migrantes Venezolanos (RAMV), así "Maicao ha recibido un porcentaje cercano al $45 \%$ del total de migrantes registrados en RAMV" (p. 37). Esta situación se evidenció, además, en los testimonios de los entrevistados. Uno de ellos, por ejemplo, señaló que "Maicao se ha convertido en un municipio receptor de los migrantes procedentes de Venezuela que ha generado una crisis económica y social a raíz del número de personas que han llegado del vecino país" (Entrevistado 3).

El tercer factor propuesto por Monetti (2016), referido a la composición de clase social, también se hace presente en el municipio de Maicao. Así, algunos de los entrevistados sostienen que los migrantes que llegan al municipio son personas de bajos recursos económi- 
cos, sociales y culturales: "Gente pobre, de extrema pobreza, no sabe trabajar [...] vivían a la costilla del gobierno venezolano, [el cual] les daba todo [...] saben solamente pedir" (Entrevistado 4).

El volumen del movimiento migratorio, su duración y la clase social de quien migra se han convertido en los tres elementos que más inciden en la percepción y las actitudes que tienen los habitantes autóctonos de Maicao sobre la migración de venezolanos. De manera general los entrevistados han percibido este proceso como problemático, ya que afecta la convivencia en el municipio y se ha vinculado con problemas de salud, seguridad, mercado laboral, entre otros. En palabras de uno de los entrevistados, "el éxodo de los venezolanos nos ha traído unas consecuencias al municipio y al territorio, como la proliferación de enfermedades, la violencia se ha disparado, en fin, una serie de situaciones por el intercambio cultural" (Entrevistado 2).

Datos de Migración Colombia (2018) señalan que el 16\% de la población residente en Maicao es inmigrante. Este alto porcentaje en un municipio relativamente pequeño y caracterizado por su bajo nivel socioeconómico se convierte en un factor problemático (Restrepo \& Jaramillo, 2018). El estudio realizado por el Observatorio Permanente Andaluz de las Migraciones (2017) sobre las opiniones y actitudes de la población andaluza ante la inmigración sostiene que en los municipios más pequeños y con alta concentración de inmigrantes surgen de manera rápida y espontanea prejuicios y estereotipos sobre éstos, además se crea la idea de que la convivencia es difícil y conflictiva. Tal situación se presenta en Maicao, donde la percepción general que tienen los entrevistados sobre la migración de los venezolanos es negativa, ya que a estos se les atribuye una serie de problemas sociales, que, si bien no necesariamente tienen en la migración su origen, sí son considerados como un factor que los acrecienta, pues se considera que su presencia es excesiva.

Sobre este último punto vale la pena mencionar que no todos los migrantes que entran por el puesto de control fronterizo de Paraguachón se quedan permanentemente en el municipio de Maicao, sino que desde esta localidad se desplazan a otras áreas geográficas de Colombia, convirtiendo a esta zona en un espacio de tránsito permanente entre ambos países. Dicha situación genera una apreciación de sobredimensionamiento del número de migrantes en el municipio.

Las percepciones negativas sobre los migrantes se pueden explicar desde la teoría del conflicto grupal, según la cual "los con- 
textos económicos adversos y de elevada presencia de inmigrantes incrementan la competencia intergrupal por bienes limitados y la consiguiente percepción de la inmigración como amenaza económico-laboral" (Cea, 2016, p. 131). Al respecto, algunos entrevistados manifiestan que:

Inicialmente la llegada de los venezolanos a Colombia disminuyó el valor de la mano de obra debido a que estos ofrecían su trabajo a menos precio que los colombianos. Dicha situación también generó algunas cuestiones de explotación laboral, ya que no se les ofrecían salarios justos y debían cumplir extensas jornadas laborales, por tanto, se originaron una serie de situaciones conflictivas con relación al mercado laboral. (Entrevistado 6)

La teoría del conflicto grupal plantea que tanto las condiciones económicas del país receptor como el número de migrantes percibido determinan su consideración como amenaza y su resultante efecto en el rechazo a la inmigración, es decir, la competencia por los recursos escasos aumenta las tensiones entre autóctonos y migrantes generando problemas de inclusión e integración social. Uno de los líderes sociales entrevistados hace evidente este conflicto grupal:

La situación con los migrantes ha empeorado la situación del municipio, ya se perciben las rupturas en la relación entre la comunidad local y el migrante venezolano, y esto es consecuencia de que el poblador local está viendo que los pocos recursos que se reciben se están direccionando para prestar ayuda al migrante y al refugiado. (Entrevistado 5)

Pero, además, desde los representantes de las autoridades locales también se percibe este tipo de situación:

La situación migratoria es una migración masiva y es un desastre social, ya que genera una gran demanda de servicios que no se pueden satisfacer, porque sobrepasa la capacidad del gobierno municipal, es decir que tenemos una presión social frente a esto [escasez de recursos] que nos ha generado una crisis humanitaria y sanitaria [...], esto ha comenzado a afectar la convivencia y la seguridad. (Entrevistado 3)

Por consiguiente, la percepción de la migración como un problema por parte de los entrevistados en Maicao está determinada por tres aspectos fundamentales. El primero de ellos es su distribu- 
ción territorial, es decir, el número de migrantes —ya sea este real o sobreestimado- y su concentración en determinadas zonas que establecerá el volumen y duración del flujo migratorio. En segundo lugar, la incidencia que sobre los autóctonos tiene la migración, es decir las implicaciones en la convivencia y la percepción de competencia por los recursos y servicios sociales, tales como educación, vivienda o salud, situación que está relacionada con las condiciones sociales de los migrantes que llegan a esta región. Y finalmente, la inserción en la actividad económica del municipio que definen al migrante como una amenaza económico-laboral.

Otra percepción muy presente dentro de los discursos de los entrevistados está referida a la vinculación de la migración con la inseguridad y la delincuencia. Frente a esto, algunos de los entrevistados afirman que los índices de hurto y homicidio han aumentado en el municipio en los últimos años debido a la llegada de venezolanos. "En la frontera han llegado grupos al margen de la ley a formar orden, y estos grupos cobran. Se asientan sobre todo en la parte venezolana porque allá no hay gobierno" (Entrevistado 5).

Se hace evidente que el contacto negativo puede incrementar los sentimientos de amenaza y desconfianza hacia el inmigrante, situación que se empieza a consolidar en Maicao a raíz de situaciones de violencia puntuales que han quedado grabadas en el imaginario colectivo. Así, en las entrevistas realizadas una buena parte de los participantes hacían mención a un mismo hecho de violencia que se convirtió en referente para catalogar a todos los migrantes como violentos o peligrosos. Desde las instituciones públicas se manifiesta que, aunque se observa un aumento en las cifras delincuenciales en el municipio, este incremento no puede ser atribuido exclusivamente a los migrantes.

\subsection{La percepción del migrante venezolano}

La percepción sobre el migrante venezolano determina el prejuicio y genera un estereotipo sobre aquel individuo que se queda en el municipio de Maicao, el cual, según los entrevistados, tiene unas características especiales que lo diferencian de otros migrantes venezolanos que continúan sus trayectorias migratorias hacia el interior de Colombia o hacia otros países de América Latina. Autores como Santamaría (2005) sostienen que, 
En la actualidad nos encontramos con un discurso hegemónico que también permea las representaciones y prácticas sociológicas sobre la "inmigración" en el que mediante la recurrente asociación de los migrantes a un sinfín de problemas sociales lo que puede hacerse mediante la afirmación de que sólo tienen, generan y/o exacerban problemas de orden público, educativos, urbanísticos, de convivencia o de cualquier otro tipo, su presencia, instalación y movilidad geográfica y social son (re)presentadas como un grave problema o una grave amenaza social. (p. 128)

La percepción del "otro" como migrante es construida con base en su procedencia geográfica, la cual lo define en contraposición al "nosotros" de los autóctonos, y desde esta perspectiva se construye una idea del migrante basada en aquellas cuestiones que diferencian ambos colectivos. Un entrevistado afirma:

Nosotros sin ningún tipo de preparación frente a esta llegada masiva de venezolanos. No es cualquier venezolano el que llega aquí. Así como viven allá pues se vienen a vivir acá, y tenemos el problema que llegan exigiendo derechos. Nos ha llegado una fracción de venezolanos con una cultura y una forma de pensar totalmente distinta, porque el venezolano progresista, emprendedor se va para otro lado. (Entrevistado 5)

Queda claro que la percepción del venezolano que se establece en Maicao no es la del migrante deseado para los autóctonos, ya que aquel que cumple con las características esperadas de progresista y emprendedor que lo identificarían con la imagen que se tiene del colombiano decide seguir su trayectoria migratoria a otras regiones. Este tipo de percepción corresponde con lo que Santamaría (2005) define como el migrante fantaseado. Esta situación permite establecer la diferencia entre los "otros" y "nosotros". - Por tanto, la construcción del "otro" en Maicao está determinada por ciertas características, en su mayoría negativas, que se le atribuyen al migrante venezolano, tales como su bajo nivel socioeconómico y cultural, su carácter conflictivo o su tendencia a la delincuencia. Algunos de los entrevistados evidencian esta percepción de manera explícita:

Debido a que algunas de estas personas no tienen ningún tipo de formación ni capacitación para trabajar, ha influido en el aumento del consumo de sustancias psicoactivas, consumo de alcohol, ha crecido la delincuencia, entre otras situaciones de riesgo a nivel psicosocial. (Entrevistado 6) 
Entonces la percepción que se tiene sobre el migrante venezolano en el municipio de Maicao por parte de los entrevistados es la del "otro" inferior culturalmente, que llega a la región desplazado por los problemas sociales, políticos y económicos de su país. Dicha percepción resulta ser conflictiva y estigmatizadora, ya que se puede instaurar en el imaginario colectivo, pues quienes manifiestan este tipo de percepción son los referentes sociales e institucionales en el municipio. Dicha situación, por tanto, podría generar en la comunidad actitudes generalizadas de discriminación y xenofobia hacia los migrantes.

Finalmente, esto nos lleva a retomar el concepto acuñado por Adela Cortina (2017) sobre la aporofobia. Cortina sostiene que lo que molesta de los inmigrantes es que sean pobres y no su procedencia geográfica, situación que se hace más presente en regiones como La Guajira donde la migración entre ambos países ha sido un punto clave para su desarrollo económico, social y cultural. Precisamente, en las entrevistas a los líderes y a algunos representantes de organizaciones se hizo referencia a las condiciones de vulnerabilidad social en las que se encuentran los migrantes venezolanos. Uno de los entrevistados pone en evidencia la aparofobia:

El venezolano no es un bicho raro, [...] siempre hemos tenido contacto con ellos. El problema ahora es que nunca habíamos tenido contacto con ellos en la situación en la que están ellos, ahí es donde se ha generado el conflicto. (Entrevistado 5)

Para los entrevistados, entonces, el problema fundamental parece estar en las condiciones de pobreza con las que llegan los venezolanos y no en su estatus de migrantes, pues consideran que Maicao se ha convertido en un filtro, a través del cual hacen su tránsito hacia otras ciudades de Colombia o países de América Latina aquellos migrantes venezolanos que tienen proyectos de vida más estructurados gracias a sus habilidades y competencias académicas, laborales y sociales, mientras que se quedan en el municipio aquellos que carecen de este capital social, económico y cultural.

\subsection{La competencia por los recursos escasos}

Las entrevistas permitieron observar que algunos líderes sociales y representantes de instituciones públicas y privadas perciben que la satisfacción de las necesidades básicas de los migrantes a través 
de diversas intervenciones sociales va en detrimento del bienestar de los autóctonos o por lo menos que estas deberían estar dirigidas y priorizadas a estos antes que a los extranjeros. Otros estudios han encontrado también, entre poblaciones receptoras de migrantes, esta percepción de riesgo frente a la posible pérdida o disminución de los recursos que proveen de bienestar físico y material (Mera, Martínez-Zelaya, Bilbao \& Garrido, 2017). Esta situación es conocida como amenaza real, es decir "la percepción de competición, entre el grupo anfitrión y el inmigrante, por la escasez de recursos como el empleo, los servicios sociales, la educación o la sanidad" (Ybarra \& Stephan, 1994, p. 42), la cual genera en la comunidad autóctona una percepción de riesgo sobre el poder económico y político, y el bienestar físico o material de su comunidad o de sus miembros.

Esta percepción, que es compartida tanto por los líderes de la comunidad entrevistados como por algunos representantes de organizaciones públicas y privadas, se traduce en la idea de que los migrantes venezolanos estarían recibiendo mayores ayudas y protección por parte del Estado colombiano y de las organizaciones internacionales en comparación con otros grupos sociales vulnerables del municipio de Maicao:

Porque sí es cierto que hay inmigrantes que están pasando necesidades, pero también hay familias colombianas en La Guajira que tienen hambre, que están en la calle, que están sufriendo, que tienen epidemias y que realmente no están recibiendo la ayuda pertinente. (Entrevistado 7)

Dentro de los testimonios de los entrevistados que apuntan a la competencia por los recursos escasos se mencionan cuatro ámbitos específicos del municipio; éstos son la educación, la salud, el empleo y el ambiente, de tal manera que se percibe una idea de competencia por los recursos escasos entre el migrante venezolano pobre y el autóctono en las mismas condiciones socioeconómicas, generando una tensión permanente entre ambos.

Respecto a la educación, algunos de los representantes de organizaciones públicas mencionan cómo el número de niños, niñas y adolescentes provenientes de Venezuela ha aumentado de manera significativa en los últimos años:

Este retorno llevó a que la sede del centro educativo en [población de Maicao] pasara de 13 a 30 estudiantes en tan solo un 
año. Al año siguiente este número ascendió a poco más de 100 y actualmente hay alrededor de 300 estudiantes. Por hacer parte de la “Gran Nación Wayúu”, estos niños tienen derecho a la doble nacionalidad, lo que les ha permitido tener documentación de colombianos, aunque toda su vida hayan residido en Venezuela. (Entrevistado 2)

El incremento de los estudiantes en las escuelas también genera una mayor demanda en aspectos tales como la alimentación escolar, el acompañamiento psicosocial y la ampliación de la infraestructura educativa en la región.

A estos niños, en un acto casi de saludo a la bandera, las instituciones educativas los reciben. Algunos tienen sus documentos, otros simplemente van a hacer acto de presencia en el salón, y vemos que son unos niños que vienen de hogares disfuncionales con unas condiciones especiales, no tienen el mismo desarrollo que tienen nuestros niños. (Entrevistado 5)

Sin embargo, el proceso de inclusión de los niños en el sistema educativo es esencial para asegurar la futura integración económica de los adultos y la socialización de los niños según los criterios locales (Monetti, 2017).

Por su parte, en lo referido a la salud se evidencian dos percepciones diferentes; por un lado, considerar que los migrantes venezolanos influyen de manera directa en el aumento de algunas enfermedades en el municipio y, de otra parte, que estos realizan un uso indiscriminado de los servicios de salud llegando a colapsarlos. Al respecto, un entrevistado afirma: "Hoy somos el primer índice en VIH del país, yo me atrevería a decir a nivel mundial de toda clase de enfermedad sexual" (Entrevistado 4).

Es especialmente recurrente el tema de las infecciones de transmisión sexual (ITS) dentro de las narrativas de los entrevistados. Sin embargo, este análisis debe ser mucho más complejo, y no limitarse a vincular de manera directa al migrante con las ITS, ya que los determinantes sociales en salud juegan un papel fundamental en la incidencia de las enfermedades dentro de ciertas poblaciones. Para el caso de los migrantes, la falta de acceso a educación en salud sexual y reproductiva, a métodos anticonceptivos, a asistencia médica oportuna y el incremento en el consumo de sustancias psicoactivas pueden estar originando una mayor incidencia de este tipo de infec- 
ciones. Esta situación ha sido identificada por algunos de los representantes de las organizaciones privadas. Uno de ellos por ejemplo señaló "Yo no diría de pronto que han traído enfermedades, sino que las mismas secuelas de la crisis los han obligado a tener esas prácticas que no son las más adecuadas, eso viene asociado al mismo tejido social deteriorado" (Entrevistado 6).

En cuanto al uso de los servicios de salud se evidencia que los entrevistados reconocen que existen ciertas dificultades en Venezuela para que sus ciudadanos puedan acceder a estos en su país de origen y por eso deben migrar a Colombia: “.Principalmente la salud, porque ellos vienen a buscar la ayuda de un médico, a buscar medicamentos que allá no hay" (Entrevistado 6).

Sin embargo, se pone de manifiesto que el municipio de Maicao no está en capacidad de atender a los migrantes que llegan y requieren de este y otros servicios sociales,

Al hospital, que es nuestro eje central en atención en salud, pues se le ha dado la responsabilidad de atenderlos, pero solamente se está atendiendo la parte de las emergencias; hay unos subsidios, unos aportes que se les están brindando. Se cree, porque no tenemos estadísticas claras [...], [que] estamos hablando de aproximadamente 40 mil. No estamos preparados para esa gente. (Entrevistado 5)

En estos casos, los líderes comunitarios y los representantes de organizaciones públicas y privadas ven en la migración de los venezolanos una amenaza para el bienestar de su comunidad, ya que relacionan la migración con el aumento de enfermedades y con el incremento en la demanda de servicios médicos.

En cuanto al empleo, los entrevistados tiene una percepción de que la migración afecta de forma negativa al mercado laboral, ya que sostienen que aumenta la competencia desleal en el ámbito laboral entre los autóctonos y los migrantes. En palabras de un entrevistado: "Agarraban a los venezolanos porque era un trabajo más barato, ha venido como desplazando a la población colombiana, por lo barato del trabajo de ellos, y no solo se vive aquí en Maicao, sino a nivel nacional" (Entrevistado 2).

Sin embargo, tras esta afirmación se debe analizar la situación que viven los migrantes que se encuentran empleados en el municipio, ya que estos sufren una discriminación que viene fomentada por las prácticas de los empleadores al imponerles extensas jornadas 
laborales que no aceptaría un colombiano, salarios por debajo de lo que establece la ley y la eliminación de cualquier tipo de prestación social. Uno de los entrevistados sostiene: "Les pagan muy mal por su trabajo o, inclusive, los encierran, lo cual es como una 'esclavitud laboral"' (Entrevistado 3).

En este sentido, no existiría una competencia desleal fomentada por los migrantes, sino una explotación de estos debido a las necesidades y la vulnerabilidad que tienen, así "el empresario se aprovecha de la situación social del inmigrante, pero también reproduce un imaginario social, el considerar al 'otro' como inferior y susceptible de ser explotado” (Sánchez, 2003, p. 7).

De otro lado, existe una percepción relacionada con el ambiente, específicamente con el tema del agua potable, el espacio público y la disposición de residuos sólidos, que también generan una sensación de competencia entre los autóctonos y los migrantes. Uno de los entrevistados manifiesta que: "Es un municipio sin fuentes hídricas. El agua no es potable y no es suficiente, y esto genera una gran problemática" (Entrevistado 3).

De modo que, los residentes de Maicao consideran que el servicio de agua potable no reúne las condiciones de calidad y cantidad que aseguren el servicio para su municipio, afirmando que la llegada de los migrantes aumentará la deficiencia en la prestación del mismo.

Otro de los aspectos relacionados con el tema ambiental es la disposición de residuos sólidos. Algunos entrevistados aseveran que este problema se ha incrementado con el aumento de los flujos migratorios. En palabras de uno de ellos "el movimiento constante de veinte mil venezolanos en crisis aumenta la producción de residuos en el espacio público" (Entrevistado 5). Otro entrevistado señala: "Se observa que estas personas [los migrantes] hacen sus necesidades fisiológicas en cualquier sitio, lo que crea problemas de salud pública, también se evidencia mayor cantidad de basuras en las calles" (Entrevistado 2).

Finalmente, dentro del tema ambiental se menciona la ocupación del espacio público por parte de los migrantes, ya que con la llegada de los venezolanos se ha incrementado el número de comercios informales que a su vez han impactado de manera negativa sobre el uso de estos espacios. Sobre este tema, González (2017) plantea que

En el espacio público, concebido sólo como un lugar de tránsito, pueden ocurrir interrelaciones momentáneas, pero no 
permanentes, mientras que — contrariamente- la actividad comercial de los vendedores, en este caso migrantes pobres, precisa de la presencia física y prolongada en el tiempo para su ejercicio. Por ende, este hecho supone un uso ilegítimo de ese espacio, ya que se convierte en un lugar donde esos sectores sociales "resuelven" necesidades que, desde la perspectiva de los sectores integrados, deberían encontrar "soluciones privadas". (p. 86)

La utilización del espacio público para las ventas informales está relacionada con las altas tasas de desempleo e informalidad laboral que se presentan en el municipio, así, el CONPES (2018) señala que en los departamentos fronterizos "la tasa de informalidad en el empleo asciende al $80 \%$, que representa un veinte por ciento más que el promedio nacional" (p. 20). Por tanto, el principal recurso que tienen los migrantes es el de dedicarse a las actividades relacionadas con la economía sumergida, es decir, verse forzados al subempleo.

De esta manera, como plantean Cosacov y Perelman (2011, citado en González, 2017), el empleo informal en el espacio público consolida el "estigma de seres excluidos que 'escogen' dedicarse a este tipo de actividades económicas ensombrece la identidad de determinados grupos de migrantes. [...] la venta callejera es asociada con el desorden y la suciedad, generando una suerte de inseguridad sanitaria"' (p. 87). Esta percepción se hace evidente en las diferentes narrativas de los entrevistados.

\section{CONCLUSIONES}

El movimiento migratorio de los venezolanos hacia Colombia presenta unas características particulares en cuanto a su intensidad y duración, ya que en un corto tiempo han ingresado al país una cantidad significativa de ciudadanos venezolanos, situación que ha condicionado la forma en la cual se percibe esta realidad, ya que Colombia nunca había experimentado un proceso de inmigración de tal magnitud. En este sentido, para la comunidad ha sido un nuevo escenario al cual se han enfrentado en sus vidas cotidianas, y para los responsables de las organizaciones públicas y privadas el surgimiento de unas nuevas demandas sociales para las cuales no se encontraban preparados y que han debido gestionar en la medida de sus posibilidades y competencias. 
Los flujos migratorios entre Colombia y Venezuela han sido constantes a través de los años, aunque no en la magnitud que se presentan actualmente. Para el caso del municipio de Maicao estos procesos han sido favorecidos por el intercambio comercial que se da entre ambos países, fomentado por su cercanía geográfica y por las relaciones culturales que se establecen gracias a la presencia de la comunidad indígena Wayúu. Sin embargo, se evidencia en los discursos de los entrevistados una doble percepción sobre el migrante venezolano, por un lado, se lo define como "hermano" ya que se reconoce el vínculo social, económico, cultural e histórico que une a ambos países y a sus comunidades, pero, por otro lado, se ha creado una imagen del migrante que lo vincula con la marginación y la delincuencia, situación que es compartida tanto por los líderes comunitarios como por algunos representantes de las organizaciones públicas y privadas (Restrepo \& Jaramillo, 2018).

El tópico del migrante de bajas condiciones socioeconómicas es el más difundido entre los entrevistados, el cual determina que su proceso de llegada al municipio de Maicao sea catalogado como problemático, ya que el discurso dominante establece una asociación permanente entre el migrante y los problemas sociales, entre estos: la alta demanda de servicios de salud y educación, la utilización inadecuada del espacio público, la violencia y los problemas de convivencia.

Las percepciones que se presentan en los entrevistados en Maicao son consistentes con la teoría del conflicto grupal, la cual establece que en contextos económicos desfavorables y con una elevada presencia de migrantes se incrementa la competencia por bienes y servicios sociales que son limitados, lo cual origina que la inmigración sea considerada una amenaza para los autóctonos, especialmente en el campo económico y laboral, es decir, una amenaza material. Sin embargo, no se presentan indicios entre los discursos de los entrevistados que apunten a que existe una percepción de amenaza simbólica, es decir, aquella que pueda afectar la identidad cultural de la región, al considerar que la llegada de migrantes pueda modificar los valores, la cultura, el lenguaje, o las tradiciones propias del municipio, y en este sentido es necesario reconocer que la cercanía cultural y social entre ambos países, y específicamente en el municipio de Maicao, debe ser considerada como una potencialidad para gestionar la migración en la región. 


\section{REFERENCIAS BIBLIOGRÁFICAS}

Álvarez de Flores, R. (2004). La dinámica migratoria colombo-venezolana. Evolución y perspectiva actual. Geoenseñanza, 9(2), 191-202. Recuperado de http://www.saber.ula.ve/handle/123456789/20988

Aparici, R. (1993). La revolución de los medios audiovisuales. Madrid: Ediciones de la Torre.

Bologna, E., \& Falcón, M. (2016). Migración sur-sur: factores relacionales e inserción segmentada de la población boliviana y peruana en la ciudad de Córdoba, Argentina. Revista Estudios Demográficos y Urbanos, 31(3), 729-773. Recuperado de https://estudiosdemograficosyurbanos.colmex. mx/index.php/edu/article/view/13/1754

Bourhis, R. Y., Moïse, L. C., Perreault, S., \& Senécal, S. (1997). Towards an interactive acculturation model: a social psychological approach. International Journal of Psychology, 32(6), 369-386. doi: 10.1080/002075997400629

Carmona-Halty, M., Navas, M., \& Rojas-Paz, P. (2018). Percepción de amenaza exogrupal, contacto intergrupal y prejuicio afectivo hacia colectivos migrantes latinoamericanos residentes en Chile. Revista Interciencia, 43(1), 23-27. Recuperado de https://www.interciencia.net/wp-content/ uploads/2018/01/23-CARMONA-43_1.pdf

Castells, M. (1997). La era de la información: economía, sociedad y cultura. El poder de la identidad. México, D. F.: Alianza Editorial.

Cea, M. A. (2002). La medición de las actitudes ante la inmigración: evaluación de los indicadores tradicionales de "racismo". Revista Española de Investigaciones Sociológicas, 99, 87-111. Recuperado de http://www.reis. cis.es/REIS/PDF/REIS_099_06.pdf

Cea, M. A. (2016). Percepción social de las migraciones en España. Panorama Social, 24, 129-144. Recuperado de https://www.funcas.es/publicaciones_new/Sumario.aspx?IdRef=4-15024

Consejo Nacional de Política Económica y Social (CONPES). (2018). Estrategia para la atención de la migración desde Venezuela (Documento 3950). Recuperado de https://colaboracion.dnp.gov.co/CDT/Conpes/ Econ\%C3\%B3micos/3950.pdf

Cortina, A. (2017). Aporofobia, el rechazo al pobre. Un desafío para la democracia. Barcelona: Paidós.

De la Vega, I., \& Vargas, C. (2014). Emigración intelectual y general en Venezuela: Una mirada desde dos fuentes de información. Bitácora-e. Revista Electrónica Latinoamericana de Estudios Sociales, Históricos y Culturales de la Ciencia y la Tecnología, 1, 66-92. Recuperado de http://www.saber. ula.ve/handle/123456789/38748

Dovidio, J. F., \& Gaertner, S. L. (2010). Intergroup bias. En S. T. Fiske, D. T. Gilbert \& G. Lindzey (Eds.), The Handbook of Social Psychology (pp. 1084-1121). Hoboken: John Wiley \& Sons Inc. 
Echeverry, A. A. (2011). Análisis de la migración venezolana a Colombia durante el gobierno de Hugo Chávez (1999-2011). Identificación de capital social y compensación económica. Revista Análisis Internacional, 1(4), 11-32. Recuperado de https://revistas.utadeo.edu.co/index.php/RAI/ article/view/84/88

García, M., \& Restrepo, J. (2019). Aproximación al proceso migratorio venezolano en el siglo XXI. Revista Hallazgos, 16(32), 63-82. doi: 10.15332/2422409X.5000

González, A. (2017). La construcción de la "peligrosidad" del migrante: un análisis sobre las representaciones sociales de miembros del sistema judicial en la Ciudad Autónoma de Buenos Aires. Estudios Socio-Jurídicos, 19(2), 63-95. doi: 10.12804/revistas.urosario.edu.co/sociojuridicos/a.5423

Holstein, N. (2010). El pueblo wayuu de la Guajira colombo-venezolana: un panorama de su cultura. Cuadernos de Antropología, 20, 1-26. Recuperado de https://revistas.ucr.ac.cr/index.php/antropologia/article/ view/2006/1973

Internal Displacement Monitoring Centre (2017). Global Internal Displacement Database. Recuperado de http:/www.internal-displacement.org/ database/displacement-data

Koolhaas, M., Prieto, V., \& Robaina, S. (2017). Los uruguayos ante la inmigración. Encuesta nacional de actitudes de la población nativa hacia inmigrantes extranjeros y retornados (Documento Núm. 1). Recuperado de https://www.colibri.udelar.edu.uy/jspui/bitstream/20.500.12008/19985/1/ DT\%20PP\%202017-01.pdf

Light, D., Keller, S., \& Calhoun, C. (1991). Sociología. Bogotá, D. C.: Editorial Mc. Graw Hill.

Observatorio Permanente Andaluz de las Migraciones (OPAM). (2017). Opiniones y actitudes de la población andaluza ante la inmigración. Recuperado de http://www.juntadeandalucia.es/justiciaeinterior/opam/sites/ default/files/DOC/Informe_final_OPIA_publicaci\%C3\%B3n_1.pdf

Organización Internacional para las Migraciones (OIM). (2006). Glosario sobre Migración (Núm. 7). Recuperado de https:/publications.iom.int/ system/files/pdf/iml_7_sp.pdf

Mancha, J. (2018). Prejuicios, estereotipos y xenofobia en comentarios de lectores de prensa digital. El caso de una niña musulmana en el diario El País. Revista Alternativas. Cuadernos de Trabajo Social, 25, 9-31. doi: 10.14198/ALTERN2018.25.01

Massey, D. S., Arango, J., Graeme H., Kouaouci, A., Pellegrino, A., \& Taylor, E. (1993). Theories of international migration: A review and appraisal. Population and Development Review, 19(3), 431-466. doi: 10.2307/2938462

Mera, M., Martinez-Zelaya, G., Bilbao, M., \& Garrido, A. (2017). Chilenos ante la inmigración: un estudio de las relaciones entre orientaciones de aculturación, percepción de amenaza y bienestar social en el Gran Concepción. Universitas Psychologica, 16(5), 1-14. doi: 10.11144/Javeriana.upsy16-5.cier 
Migración Colombia. (2017). Radiografía de venezolanos en Colombia. Recuperado de http://www.migracioncolombia.gov.co/venezuela/radiogra fia_web.pdf

Migración Colombia. (2018). Informe final. Registro Administrativo de Migrantes Venezolanos (RAVM). Recuperado de https://www.refworld.org. es/pdfid/5b2957524.pdf

Monetti, M. (2016). Las migraciones internacionales y el proceso de integración en las sociedades de acogida: una mirada desde las teorías sociológicas contemporáneas. Fronteras, 3(2), 7-42. Recuperado de http:// revistas.ufro.cl/ojs/index.php/fronteras/article/view/645

Montero, G. (2006). Las representaciones sociales de los emigrantes ecuatorianos en España sobre el proceso migratorio. Revista Alternativas. Cuadernos de Trabajo Social, 14, 35-48. doi: 10.14198/ALTERN2006.14.3

Oroza, R., \& Puente, Y. (2017). Migración y comunicación: su relación en el actual mundo Globalizado. Revista Novedades en Población, 13(25), 10 16. Recuperado de http://www.novpob.uh.cu/index.php/NovPob/article/ view/249

Portes, A., Guarnizo, L., \& Landolt, P. (2003). La globalización desde abajo: transnacionalismo inmigrante y desarrollo: La experiencia de Estados Unidos y América Latina. México, D. F.: FLACSO.

Restrepo, J. E., \& Jaramillo, J. (2018). Venezuelans in Colombia: Understanding the implications of the migrants crisis in Maicao (La Guajira). Sayara International. Recuperado de https://sayarainternational.com/ wp-content/uploads/2019/05/Report-Venezuelans-in-Colombia-SayaraInternational-Final-Version.pdf

Robayo, M. (2013). Venezolanos en Colombia, un eslabón más de una historia compartida. Recuperado de http://www.urosario.edu.co/urosario_ files/2e/2ee3361e-eec6-4230-925b-3e6d91c83ab0.pdf

Reina, M., Mesa, C. A., \& Ramírez, T. (2018). Elementos para una política pública frente a la crisis de Venezuela. Bogotá, D. C.: Fedesarrollo. Recuperado de https://www.repository.fedesarrollo.org.co/handle/ $11445 / 3680$

Santana, D. (2009). Geografía de la inmigración venezolana en Colombia entre 1993 y 2008.Ar@cne, 124, s. p. Recuperado de http://www.ub.edu/ geocrit/aracne/aracne-124.htm

Santamaría, E. (2005). De migraciones, sociologías e imaginarios. Revista Sociedad y Economía, 9, 121-136. Recuperado de http://sociedadyeconomia.univalle.edu.co/index.php/sociedad_y_economia/issue/view/408

Sánchez, R. (2003). Apuntes para una reflexión: el "otro" inmigrante. Nómadas: Critical Journal of Social and Juridical Sciences, 8, s. p. Recuperado de http://theoria.eu/nomadas/8/rsgarrido.htm-

Vargas, L. (1994). Sobre el concepto de percepción. Alteridades, 4(8), 47-53. Recuperado de https://alteridades.izt.uam.mx/index.php/Alte/article/ view/588/586 
Weeks, J. R. (1990). Sociología de la población. Introducción a los conceptos y cuestiones básicas. Madrid: Alianza Editorial.

Ybarra, O. J., \& Stephan, W. G. (1994). Amenaza percibida como predictor de prejuicios y estereotipos. Reacciones de los americanos a los inmigrantes mejicanos. Boletín de Psicología, 42, 39-54. Recuperado de https://www.uv.es/seoane/boletin/previos/N42-3.pdf 